\title{
Validation of International School Climate Surveys in Slovakia
}

\author{
Eva Gajdosova, Silvia Majercakova Albertova \\ Department of School Psychology, Faculty of Psychology, Paneuropean University, Bratislava, Slovakia \\ Email address: \\ eva.gajdosova@paneurouni.com (E. Gajdosova), silvia.albertova@paneurouni.com (S. M. Albertova)

\section{To cite this article:} \\ Eva Gajdosova, Silvia Majercakova Albertova. Validation of International School Climate Surveys in Slovakia. American Journal of Applied \\ Psychology. Vol. 8, No. 1, 2019, pp. 14-18. doi: 10.11648/j.ajap.20190801.13
}

Received: February 17, 2019; Accepted: March 26, 2019; Published: April 18, 2019

\begin{abstract}
This paper summarizes the first pilot research results from the study of school climate in Slovak primary and secondary schools. The research was conducted as part of the Cross-Cultural School Climate Study project using the Georgia school climate surveys, adapted to Slovak conditions. Participants were 832 primary and secondary students, 125 school personnel and 614 parents. Results indicate overall positive ratings of school climate across all participant groups. Students provided the highest ratings in the domains of character, peer social support and school safety. The lowest ratings were reported in the domain of cultural acceptance. School personnel provided the most positive ratings of school climate among the participant groups, followed by parents. Both participant groups reported the highest ratings for school safety and the lowest ratings for parent involvement.
\end{abstract}

Keywords: Validation, School Climate, Survey, School

\section{Introduction}

Positive social climate in schools and social relationships based on trust, support, help and tolerance of differences have a significant positive effect on life satisfaction of students and teachers, their wellbeing and their quality of life. Positive social climate in school has also been associated with good mental health of students and teachers as well as with positive personality development [1].

Social climate in school, also known as school climate, has been variously defined and in literature is referred to as school atmosphere, school culture, school environment or social system of school [2]. Prucha, Walterova \& Mares [3 p 107] define school climate as a

"social psychological variable, which expresses the quality of interpersonal relationships and social processes of a particular school in a way that is perceived, experienced and evaluated by teachers, students and other school personnel. A component of school climate is for instance climate among the teaching staff, climate in school classes, climate of overall school environment, etc.".

According to Petlak [2], school climate in the broad sense comprises relationships between personality and environment. Social climate as a school culture is comprised of values, norms, attitudes and climate as a compound of subjective views of participating individuals and mutual relationships of individuals involved in school life. In a narrow sense, school climate may be viewed as "an organizational ideology representing school values and goals, climate as a mood, as a mental state, as a class climate or climate as a mediator between students and teachers" [2 $p$ 15]. School climate is a relatively stable aspect of the internal school environment and is created by individuals associated with the school - students, parents and all school personnel, i.e. not only the teaching and professional staff but also administrative staff, caretakers and canteen staff [4].

School climate is an individual as well as a group phenomenon which includes values and attitudes shared by the students, parents and school personnel and which impacts mutual interactions within the school. School climate also determines the norms of behavior that are considered acceptable or unacceptable within the school. Research has found that school climate is positively associated with academic success and negatively associated with risk behavior of students, including bullying [5-7].

This school climate research in Slovak primary and secondary schools was conducted as part of the international Cross-Cultural School Climate Study research project. 12 
countries participated in the project in this initial research phase: Belgium, Malta, Latvia, Jamaica, Greece, Germany, the USA, Japan, Italy, Hungary, Great Britain and Slovakia. The project has been led by a primary research team from the University of Connecticut, USA and financed by a grant provided by the International School Psychology Association. Research in Slovakia was coordinated by the Department of School Psychology at the Paneuropean University in Bratislava, under the lead of prof. PhDr. Eva Gajdosova, $\mathrm{PhD}$ and her research team.

The goals of the Cross-Cultural School Climate Study project are as follows: translation and adaptation of school climate surveys into the languages of the participating countries, validation of surveys in different cultural contexts and examination of cross-cultural similarities and differences in the perceptions of school climate. The intention is to establish a set of school climate surveys that can be used internationally. Indirectly, research results may be used as an indicator for improvement of school climate in individual countries.

The goal of the research in Slovakia was to validate international school climate surveys adapted to Slovak conditions and to investigate aspects of school climate from various viewpoints of students, school personnel and parents in primary and secondary schools.

\section{Method}

\subsection{Participants}

The research in Slovakia was conducted in four primary and secondary schools in the city of Bratislava during school year 2017/2018. The participating schools were three state schools and one private inclusive school. Participants of the study were 529 primary students and 303 secondary students, in total 832 students from grades 3 to 9.125 teaching and non-teaching school personnel and 614 parents also participated in the study. In total, 1,571 participants from three groups - students, parents and school personnel responded to the surveys.

\subsection{Measures}

Georgia School Climate Surveys [8, 9, 10, 11] were used as measures in the Cross-cultural research project: Georgia Primary School Climate Survey, Georgia Secondary School Climate Survey, Georgia Personnel School Climate Survey and Georgia Parent School Climate Survey. English versions of the surveys were translated into Slovak, followed by back translations into English. Detailed documentation of the translation process was provided to the primary research team in the US.

The Georgia Primary School Climate Survey consists of 11 items and is suitable for students in grades 3 to 5 . It measures overall school climate. Participants rate their perception of school climate on a 4-point scale (always, often, sometimes, never).

The Georgia Secondary School Climate Survey is designed for secondary students and high school students. It consists of 44 items and 9 subscales: connectedness, character, physical environment, adult social support, peer social support, cultural acceptance, safety, order and discipline and mental health. Students' responses are measured on a 4-point scale (strongly disagree, somewhat disagree, strongly agree, somewhat agree).

The Georgia Parent School Climate Survey is designed for measuring the perceptions of parents or legal guardians of students on school climate. This instrument contains 21 items and 5 subscales: teaching and learning, school safety, interpersonal relationships, institutional environment and parent involvement. Responses are rated on a 4-point scale (strongly disagree, somewhat disagree, strongly agree, somewhat agree).

The Georgia Personnel School Climate Survey is an instrument for assessment of school climate by teaching and non-teaching school personnel, school management and other school employees (admin personnel, canteen and cleaning personnel, etc.). It contains 29 items and 6 subscales: staff connectedness, structure for learning, school safety, physical environment, peer and adult relations, and parent involvement. Responses are recorded on a 4-point scale (strongly disagree, somewhat disagree, strongly agree, somewhat agree).

Ratings of students, school personnel and parents were reported as an average value in the range of 0.0 to 4.0 as follows:

$0-1.5$ very negative perceptions of school climate

$1.6-2.5$ negative perceptions of school climate

$2.6-3.5$ positive perceptions of school climate

$3.6-4.0$ very positive perceptions of school climate

\subsection{Procedure}

The Slovak research team, consisting of faculty members at the Faculty of Psychology at the Paneuropean University in Bratislava, joined the Cross-Cultural School Climate Study in august 2017. Translation and back translation of surveys was conducted in two months and documentation was provided to the primary research team in the US. Institutional Review Board approval was obtained by the primary research team for all countries participating in the project.

For the first round of data collection in Slovakia, five schools were approached and four of them agreed to participate in the study. School principals received a detailed information letter about the study and were consulted on a suitable form of survey administration, which was originally planned online. The primary research team provided links to surveys for each participating country in order to facilitate data collection in 12 countries. Since a $60-70 \%$ response rate was expected for each participating school, data in Slovakia were collected in paper form in order to ensure a higher response rate, especially from parents. Data collection took place in January and February 2018. Preliminary results were made available in May 2018, and in July 2018, results for the USA, Italy, Jamaica, Latvia, Lithuania and Slovakia were presented at an International School Psychology Association conference in Tokyo, Japan. 


\section{Results}

\subsection{School Climate in Slovak Primary and Secondary Schools}

The most important finding of the international research on school climate in Slovakia was that school climate is perceived highly positively by students (2.83), school personnel (3.39) and parents (3.24).

\subsection{School Personnel Perceptions of School Climate in Slovak Schools}

School personnel provided the most positive ratings of school climate (3.39) among all participant groups, with average ratings in all subscales above 3.0 (from 3.08 for peer and adult relations to 3.62 for school safety).

Table 1. Average ratings of school climate by school personnel.

\begin{tabular}{ll}
\hline School climate subscales & Average ratings \\
\hline School Safety & 3.62 \\
Staff Connectedness & 3.57 \\
Structure for Learning & 3.46 \\
Physical Environment & 3.39 \\
Parent Involvement & 3.18 \\
Peer and Adult Relations & 3.08 \\
Average school climate rating & 3.39 \\
\hline
\end{tabular}

School personnel provided the highest rating for school safety (3.62), which is in the range of very positive perceptions. Similarly positive perceptions were recorded for staff connectedness (3.57). The lowest ratings were recorded for peer and adult relations (3.08) and parent involvement (3.18); however, both ratings are still within the range of positive perceptions.

While no significant differences were found in the perceptions of school climate by school personnel of individual schools, differences were recorded in the perceptions of school climate by teachers and non-teaching professional employees (school psychologists, occupational therapists). A statistically significant difference was found between teachers and non-teaching professional employees in the subscale peer and adult relations $(\mathrm{p}=.027)$, which indicated that non-teaching personnel perceive relations between students and adults more positively than teaching personnel. Another significant difference was found in the subscale staff connectedness ( $\mathrm{p}=.044)$, with non-teaching professional employees providing higher ratings than teachers. An interesting finding is that the highest ratings for peer and adult relations and staff connectedness were provided by school management.

\subsection{Parents' Perceptions of School Climate in Slovak Schools}

The average perceptions of school climate by parents in participating schools were positive (3.24) in terms of overall perceptions as well as in terms of individual subscales. Results indicated the highest ratings for school safety (3.52), institutional environment (3.29) and interpersonal relationships (3.27). It is noteworthy that parents were critical of their own involvement in school matters and provided the lowest ratings for the subscale parent involvement (2.77). This is the only school climate subscale where the rating falls below 3.0 .

Table 2. Average ratings of school climate by parents.

\begin{tabular}{ll}
\hline School climate subscales & Average ratings \\
\hline School Safety & 3.52 \\
Institutional Environment & 3.28 \\
Interpersonal Relationships & 3.26 \\
Teaching and Learning & 3.08 \\
Parent Involvement & 2.77 \\
Average school climate rating & 3.24 \\
\hline
\end{tabular}

Parental ratings indicated statistically significant differences in the perceptions of overall school climate among participating schools as well as in the subscales teaching and learning (3.08), interpersonal relationships (3.27) and parent involvement $(2.77 ; \mathrm{p}<.001)$, which are all in favor of private inclusive school. It was confirmed that the private inclusive school received the highest ratings in overall school climate as rated by parents. Moreover, ratings for teaching and learning for this school were in the range of very positive perceptions and ratings for interpersonal relationships were also very positive.

Statistically significant differences between the private inclusive school and the three state schools were found in interpersonal relationships. The approach of positive psychology and having an emphasis on wellbeing, happiness and contentment have proven to have a positive impact on relationships in the inclusive school.

\subsection{Students' Perceptions of School Climate in Slovak Schools}

The average rating of school climate by primary students (grades 3 to 5) was 2.90 and in the case of secondary students (grades 6 to 9), it was 2.83. Overall ratings of school climate by students were higher than 2.5 and were therefore in the range of positive perceptions.

In terms of individual subscales, students provided the highest ratings for the subscale character (3.20), followed by peer social support (3.09) and school safety (2.81). The lowest ratings were recorded for cultural acceptance (2.59), which is an area that deserves further support and development in schools. A similar rating was recorded for the subscale order and discipline (2.62), where students perceived a need for improvement.

Table 3. Average ratings of school climate by students.

\begin{tabular}{ll}
\hline School climate subscales & Average ratings \\
\hline Character & 3.20 \\
Peer Social Support & 3.09 \\
Safety & 2.81 \\
School Connectedness & 2.78 \\
Adult Social Support & 2.78 \\
Physical Environment & 2.64 \\
Order and discipline & 2.62 \\
Cultural Acceptance & 2.59 \\
\hline
\end{tabular}




\subsubsection{Grade}

Statistically significant differences in the perceptions of school climate were found among individual grades. It was confirmed that the higher the grade, the lower the rating of school climate, i.e. primary students perceive school climate more positively than secondary students $(p<.001, p=.044)$.

Table 4. Average ratings of school climate by primary and secondary students.

\begin{tabular}{ll}
\hline Grade & Average ratings \\
\hline $3^{\text {rd }}$ grade & 3.33 \\
$4^{\text {th }}$ grade & 2.85 \\
$5^{\text {th }}$ grade & 2.65 \\
$6^{\text {th }}$ grade & 2.94 \\
$7^{\text {th }}$ grade & 2.80 \\
$8^{\text {th }}$ grade & 2.81 \\
$9^{\text {th }}$ grade & 2.76 \\
\hline
\end{tabular}

Results for individual grades further indicated that students in the $5^{\text {th }}$ grade perceived school climate least positively (2.65) out of all the grades. Similar results were obtained for the $9^{\text {th }}$ grade, where the average rating of school climate was 2.76 . In the Slovak school system, the $5^{\text {th }}$ grade is the grade of transition from primary to secondary school and it is a very demanding grade in terms of learning, organization, forms and methods of teaching, new subjects, higher performance demands and a number of new teachers. The $9^{\text {th }}$ grade is the last grade of secondary school in Slovakia. Students prepare for their transition to high school or vocational school, they face high performance expectations and prepare for official state-wide assessment Monitor 9, on which their proficiency in Slovak and math is tested. The results of this assessment are important for their entrance exams to high or vocational schools. This is a very stressful period for students with a negative impact on their perceptions of school climate.

The results indicated significant differences between grades in their perceptions of overall school climate as well as in their perceptions of individual subscales except for physical environment, order and discipline and school safety $(p>.05)$, indicating that students across the grades perceived these subscales similarly. For the other subscales (connectedness, character, adult social support, peer social support, cultural acceptance, mental health), significant differences were present. For instance, a significant difference was found in the ratings of cultural acceptance among students from grades 7 to 9 compared to younger students $(\mathrm{p}=.017)$.

\subsubsection{Gender}

There were no significant differences in the perceptions of the overall school climate by girls and boys; however, a significant difference was found in the subscale of character in favor of girls who scored significantly higher than boys ( $p$ $=.007)$.

\subsubsection{Students with Special Needs}

Students with special needs (physical disabilities, learning disorders, conduct disorders, attention deficit hyperactivity disorder (ADHD), emotional disorders) perceived school climate in their schools positively (2.84), with the highest ratings indicated by students with physical disabilities (2.83) and ADHD (2.98).

It is an encouraging result that no significant differences in perceptions of school climate were found between students with no disabilities, students with disabilities and gifted students.

The overall school climate perceptions by students are in the range of positive perceptions despite some variations in individual subscales.

\section{Discussion}

The most significant finding of the international research on school climate in Slovakia is that school climate is perceived positively by students, parents and school personnel in participating schools.

Students in primary school perceive school climate more positively than students in secondary school, with the lowest ratings indicated by students in the $5^{\text {th }}$ and $9^{\text {th }}$ grades. Both grades are considered very demanding in the Slovak school system - the $5^{\text {th }}$ grade due to transitioning from primary to secondary school and the $9^{\text {th }}$ grade due to transitioning to high or vocational school. Overall ratings of school climate by students were positive.

Students' ratings in terms of individual domains of school climate were the most positive for the domain of character, peer social support and school safety. The lowest ratings were found for the domain of cultural acceptance. Differences in the perceptions of school climate by boys and girls are insignificant. It may be considered an encouraging finding that students with special needs perceive school climate as positively as other students.

Parents perceive the overall school climate as well its individual domains positively, with the highest ratings provided for school safety, school environment and interpersonal relationships. It is interesting that parents were critical towards their own involvement in school matters and rated the domain of parental involvement the lowest out of all school climate domains. This finding indicates that this is the area where implementation of positive changes via modern forms and methods of school-parent cooperation is most desirable.

The perceptions of school personnel on school climate were the most positive in comparison to the other participant groups. Similarly to parents, teachers and other school employees indicated the highest ratings for school safety in their schools. The lowest ratings were provided for the domain of peer and adult relations and parent involvement, although both of them are still perceived positively.

Another positive finding is the finding on very positive school climate in the private inclusive school. This result is very important for Slovakia. On one hand, it proves that despite continuous mistrust towards inclusive education in Slovak schools, this type of school may have positive school climate and thus positive influence on the mental health of students and teachers. On the other hand, these results confirm that applied humanistic and positive psychology in the educational process, as it is done in this school, has a very positive influence on school climate and its individual 
domains, mostly on interpersonal relationships and teaching and learning.

The findings of the present study allow for several school psychology implications to be drawn. First, there is a need for implementation of preventative programs targeted towards the development of prosocial skills in both genders; however, specifically in boys. Second, attention should be paid to strategies for supporting cultural acceptance and tolerance to diversity since this is the area that received the lowest ratings, especially by secondary students. Third, school psychologists should focus their attention towards supporting students in the $5^{\text {th }}$ and $9^{\text {th }}$ grades, who are exposed to challenging circumstances in their school life, which is reflected in their perceptions of school climate. Parent involvement is another area where positive changes would be desirable, e.g. through application of modern forms of school-family cooperation. Lastly, school personnel, especially teachers, would benefit from opportunities to enhance their wellbeing and mental health what may in turn be reflected in more positive student teacher relations within the school.

The present study has some limitations that need to be addressed. The main limitation to be considered is the specificity of the sample. The sample consisted of schools that agreed to their participation in the study probably due to the fact that they are active in fostering positive school climate in their schools. All of the participating schools have school psychologist on staff who is responsible for caring for students' wellbeing, which is reflected on how students perceive their school climate. Future research could expand the current findings by including a more diverse sample of schools from different regions of Slovakia.

\section{Conclusion}

This paper presents the results of a school climate research in Slovak primary and secondary schools which was conducted as part of the Cross-Cultural School Climate Study, involving 12 countries. The battery of Georgia School Climate Surveys was used in Slovakia for the first time to assess perceptions of school climate by students, parents and school personnel. Results indicated positive perceptions of school climate by all participants. The most positive ratings were provided, in descending order, by school personnel, parents and lastly by students. Both school personnel and parents perceived the domain of school safety most positively and the domain of parent involvement in school least positively. Students perceived the domains of character, peer social support and school safety most positively and the domain of cultural acceptance least positively.

It may be concluded that this preliminary school climate research in Slovakia provided positive results as well as positive experience with the use of school climate surveys in schools, which, upon approval of the authors and the publishing company, may be used statewide within the battery of assessments used by school psychologists in Slovak primary and secondary schools. Overall, the results have indicated possibilities for broad use of the school climate surveys, mainly in the area of evaluation and selfevaluation of school quality.

Findings from the school climate study were presented at an international conference organized by the School Psychology Association in Tokyo, Japan, 25 to 28 July 2018, by Silvia Majerčáková Albertová, M. A., member of the research team from the Faculty of Psychology at the Paneuropean University under the title International Perspectives on School Climate.

\section{Acknowledgements}

We thank our colleagues from the international research team under the lead of Dr. Tamika La Salle of the University of Connecticut for the opportunity to participate in the CrossCultural School Climate Study and to validate school climate surveys in Slovak schools. We are grateful for their excellent support, assistance and professional attitude throughout the project.

\section{References}

[1] Gajdošová, E. (2015). Školská psychológia a školský psychológ v 21. storočí. Bratislava: Eurokódex.

[2] Petlák, E. (2006). Klíma škola a klíma triedy. Bratislava: Iris.

[3] Prucha, J., Walterová, J. \& Mareš, J. (1998). Pedagogický slovník. Praha: Portál.

[4] Mareš, J., (2009). Sociální klíma školní třídy [online]. Available http://klima.pedagogika.cz/trida/doc/Mares_Klima_tridy.

[5] Bear, G. C., Gaskins, C., Blank, J., and Chen, F. F. (2011). Delaware school climate survey-Student: Its factor structure, concurrent validity, and reliability. Journal of School Psychology, 49, 157-174.

[6] Koth, C. W., Bradshaw, C. P., \& Leaf, P. J. (2008). A multilevel study of predictors of student perceptions of school climate: The effect of classroom-level factors. Journal of Educational Psychology, 100 (1), 96-104. doi: 10.1037/00220663.100.1.96.

[7] Kuperminc, G. P., Leadbeater, B. J., \& Blatt, S. J. (2001). School social climate and individual differences in vulnerability to psychopathology among middle school students. Journal of School Psychology, 39, 141-159.

[8] La Salle, T. P \& Meyers, J. P. (2014) The Georgia Student Health Survey 2.0. Atlanta, GA: Georgia Department of Education.

[9] La Salle, T. P. \& Meyers, J. P. (2014) The Georgia School Personnel Survey. Atlanta, GA: Georgia Department of Education.

[10] La Salle, T. P. \& Meyers, J. P. (2014) The Georgia Parent School Climate Survey. Atlanta, GA: Georgia Department of Education.

[11] La Salle, T. P. \& Meyers, J. P. (2014) The Georgia Elementary School Climate Survey. Atlanta, GA: Georgia Department of Education. 